\title{
Permanent magnet flux switching motor technology as a solution for high torque clean electric vehicle drive
}

Enwelum I. Mbadiwe, Erwan Sulaiman, Zarafi Md. Ahmad, M. F. Omar

Research Centre for Applied Electromagnetics, Universiti Tun Hussein Onn Malaysia, Malaysia

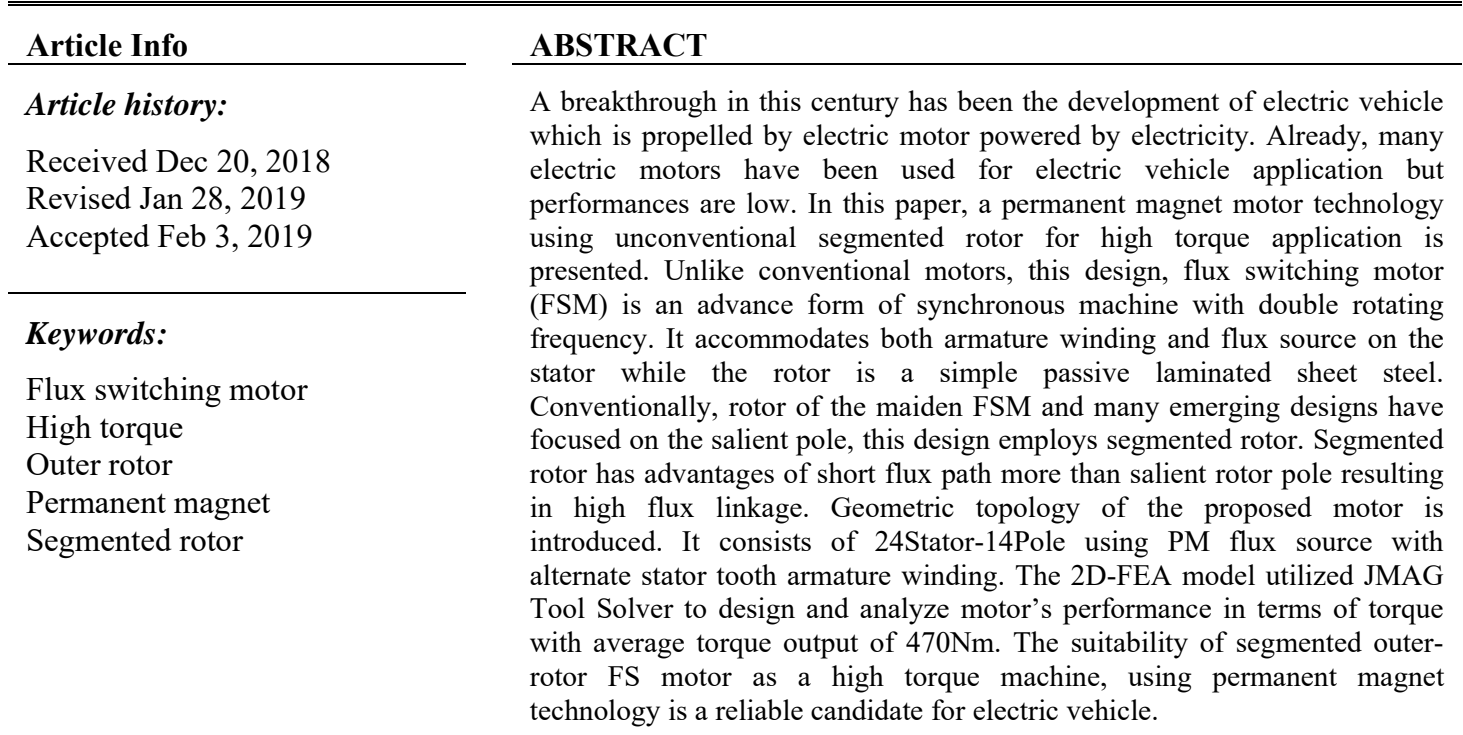

Copyright @ 2019 Institute of Advanced Engineering and Science. All rights reserved.

\section{Corresponding Author:}

Enwelum I. Mbadiwe,

Research Centre for Applied Electromagnetics,

Universiti Tun Hussein Onn Malaysia

86400, Parit Raja, Batu Pahat Johor Malaysia.

Email: mb.fkee.uthm@gmail.com

\section{INTRODUCTION}

Electric motor receives input quantities of voltage and current and converts them into output mechanical quantities of torque and speed [1] that are necessary for vehicle propulsion. High torque motors have been constantly under research and development for clean vehicle propulsion suitable for long distance travels. However, amount of torque provided by any electric motor depends primarily on the magnetic loading especially when electric loading with all parameters are constant as in the case of the proposed motor. Generally, electric machines utilize different flux sources for excitation such as; permanent magnet (PM), field excitation (FE) and hybrid excitation which combines both PM and FE [2-3]. Flux switching machine (FSM) is an advance form of synchronous machine locates both armature winding and flux source in the stator and leaving the rotor without any added material, has become researchers' choice because of speed capability [4-6]. Invariably, transferring inner rotor to outer position generates higher torque and also offers reliable control mechanism in the vehicle through eliminating complex combustion engine in conventional vehicle [7-8]. Outer rotor is suitable for in-wheel motor application which is accommodated in the rim and the normal mechanical brakes with suspension systems [9]. Consequently, PM flux has many advantages such as loss-free excitation without external circuit connections, this thereby results in to high torque density which makes it to be a dominant flux source [2]. However, only the inverter and high quality 
battery are needed in conjunction with electric motor for effective performance. In fact, application of electric motors has successfully replaced the complicated combustion engine that had dominated in conventional vehicles over a century ago [10-12].

Permanent magnet flux switching (PMFS) motor is regarded as a viable candidate in applications where high torque, wide constant speed, easy cooling and adequate fault tolerance are desired [13, 14]. Already, many PMFS motors in outer rotor configuration have been proposed $[2,3]$. The first PMFS was a single-phase in salient pole rotor [16] and its three-phase counterpart structure, was also salient pole rotor [17]. Also, various other motors have been designed for applications in domestic and aerospace in salient pole [4]. While salient pole have been known with conventional machine design, high iron and copper have continued to be associated with it in performance [19]. Material and winding losses lead to poor machine performance, it is important for research and development to explore for motor parameters with minimum iron and copper losses and high performance.

Segmented type of rotor has been applied in machine to enhance performance and the result was unprecedented. It exhibited saliency ratio that meaningfully increased torque performance compared to conventional salient pole rotor $[13,20]$. The obvious advantage of segmented rotor includes operating with a bipolar flux in the magnetic circuit. The bipolar flux linkage in the armature windings is achieved by carefully designing the rotor segment to overlap with two armature slot openings.

This papers takes a comprehensive look at flux switching machine (FSM) using segmented outer rotor (SegOR-PMFSM). It is capable of high torque performance for clean electric vehicle drive by eliminating both combustion engine and use of fuel energy. While combustion engine must require fuel oil to burn in a closed chamber before creating torque, electric motor has two simple stator and rotor parts with flux source and winding copper conductor. The interaction of field produced by the flux source and field produced by the induced current flowing through the armature conductors provide torque [18]. The motor consists of three-phase, 24Stator-14Pole, with alternate armature tooth winding and permanent magnet in radial direction. The design of the motor and performances at open circuit (or no-load condition) and closed circuit condition are investigated and outlined. Finally, the performance of PMFS motor employing segmented rotor is compared with FEFS motor and HEFS motor of similar diameter and restrictions having salient pole rotor. Figure 1 depicts conventional in-wheel flux switching motors in salient pole rotor for electric vehicle application.

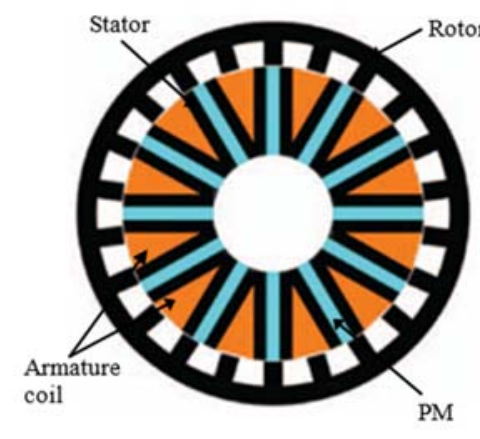

(a)

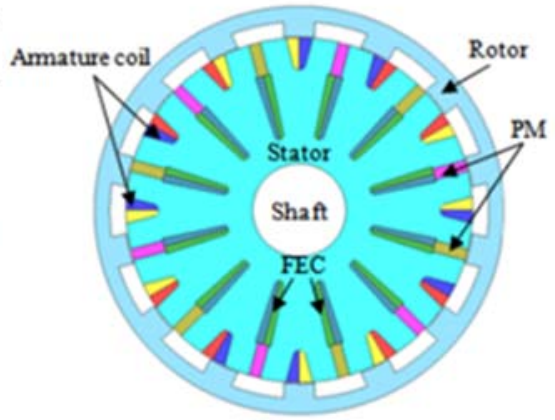

(b)

Figure 1. Conventional SFMs in outer rotor structure, (a) three- phase 12S/22P PMSFM (b) three-phase 12S/14P HESFM

\section{RESEARCH METHOD}

Design of free intial motor parameters and optimization them by deterministic method are outlined in Figure 2 and Figure 3. The characteristics performances of the improved three-phase 24Stator-14Pole segmented outer rotor (SegOR) PMFSM are investigated in terms of average torque and power obtained which were $348.6 \mathrm{Nm}$ and $45 \mathrm{~kW}$ at the maximum base speed of $1,397.8 \mathrm{rev} / \mathrm{min}$. Meanwhile, parameter specifications and restrictions are outlined in Table 1. Figure 4 shows the cross sections of the improved design. While the performance is favorable, design optimization of motor will further optimum output torque for effective performance [18]. 

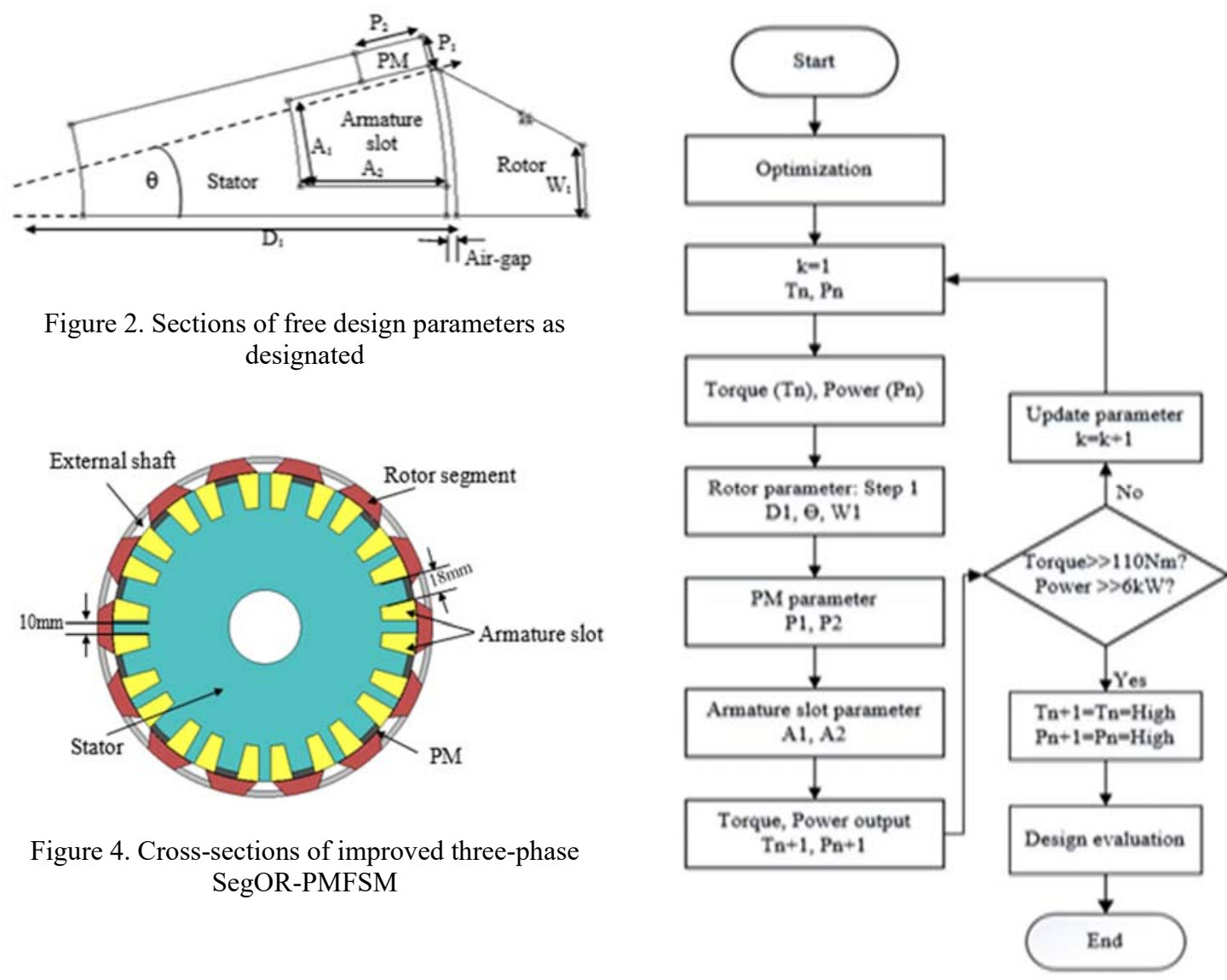

Figure 2. Sections of free design parameters as designated

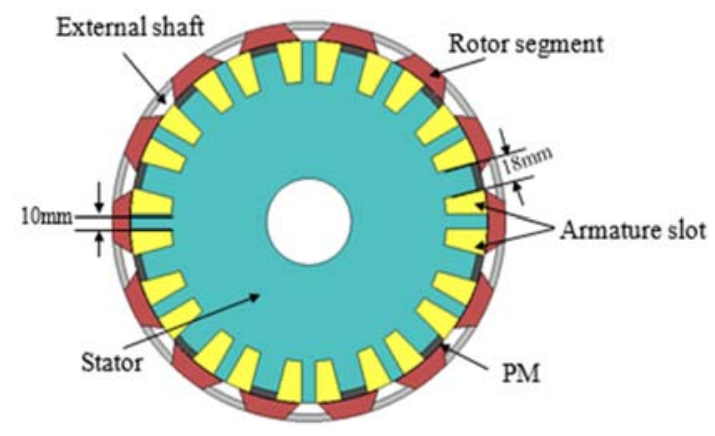

Figure 4. Cross-sections of improved three-phase SegOR-PMFSM

Figure 3. Flowchart of optimization process

Table 1. Design specifications, parameter restrictions and electrical supply

\begin{tabular}{lrr}
\hline \multicolumn{1}{c}{ Descriptions } & Improved design & Optimized design \\
\hline Motor radius $(\mathrm{mm})$ & 139.7 & 139.7 \\
Outer rotor radius $(\mathrm{mm})$ & 139.7 & 139.7 \\
Inner rotor radius $(\mathrm{mm})$ & 119.2 & 127.2 \\
Rotor pole length $(\mathrm{mm})$ & 20.5 & 12.5 \\
Rotor width $(\mathrm{mm})$ & 17.2 & 26.2 \\
Segment span (degree) & 20 & 20 \\
Stator outer radius $(\mathrm{mm})$ & 118.7 & 126.7 \\
Stator tooth width $(\mathrm{mm})$ & 10 & 10 \\
Air-gap length $(\mathrm{mm})$ & 0.5 & 0.5 \\
Magnet weight $(\mathrm{kg})$ & 1.0 & 1.0 \\
Magnet length $(\mathrm{mm})$ & 6.13 & 6.13 \\
Magnet width $(\mathrm{mm})$ & 18 & 18 \\
Stack length $(\mathrm{mm})$ & 100 & 100 \\
Stator shaft $(\mathrm{mm})$ & 30 & 30 \\
DC- input voltage $(\mathrm{V})$ & 415 & 415 \\
Inverter current $\left(\mathrm{A}_{\mathrm{rms}}\right)$ & 360 & 360 \\
Number of turn & 18 & 18 \\
Slot surface area $\left(\mathrm{mm}{ }^{2}\right)$ & 432 & 432 \\
Average torque $(\mathrm{Nm})$ & 348.6 & $>348.6$ \\
Output Power $(\mathrm{kW})$ & 50 & $>50$ \\
Rated speed $(\mathrm{rev} / \mathrm{mim})$ & $1,397.8$ & $<1,397.8$ \\
\hline
\end{tabular}




\subsection{Modeling of Motor and Park's Transformation}

The proposed three-phase segmented rotor PMFSM in terms of flux linkage, changes with rotor position, $\theta_{r}$, therefore, three-phase PM flux linkages, $u v w, \psi_{m u}, \psi_{m v}$ and $\psi_{m w}$ have been proved and given in [21]:

$$
\psi_{u v w}=\left[\begin{array}{l}
\psi_{m u}=\psi_{m} \cos \left(p \theta_{r}\right) \\
\psi_{m v}=\psi_{m} \cos \left(p \theta_{r}-\frac{2 \pi}{3}\right) \\
\psi_{m w}=\psi_{m} \cos \left(p \theta_{r}+\frac{2 \pi}{3}\right)
\end{array}\right]
$$

where $\psi_{m}$ is the magnitude of the fundamental component, $p$ is the number of rotor pole while $\theta_{r}$ is rotor position.

The armature inductances for 24S-14P PMFSM, based on 2D-FEA: Self-inductance results for the three-phase are given as

$$
\left[\begin{array}{l}
\mathrm{L}_{\text {uu }}=\mathrm{L}_{\mathrm{o}}-\mathrm{L}_{\mathrm{m}} \cos \left(\mathrm{p} \theta_{\mathrm{r}}\right) \\
\mathrm{L}_{\mathrm{vv}}=\mathrm{L}_{\mathrm{o}}-\mathrm{L}_{\mathrm{m}} \cos \left(\mathrm{p} \theta_{\mathrm{r}}+\frac{2 \pi}{3}\right) \\
\mathrm{L}_{\mathrm{ww}}=\mathrm{L}_{\mathrm{o}}-\mathrm{L}_{\mathrm{m}} \cos \left(\mathrm{p} \theta_{\mathrm{r}}-\frac{2 \pi}{3}\right)
\end{array}\right]
$$

where $\mathrm{L}_{\mathrm{o}}$ is the component of self- inductance and $\mathrm{L}_{\mathrm{m}}$ is the magnitude of fundamental piece while mutual-inductances are expressed as:

$$
\left[\begin{array}{l}
\mathrm{M}_{\mathrm{uv}}=\mathrm{M}_{\mathrm{vu}}=\mathrm{M}_{\mathrm{o}}-\mathrm{M}_{\mathrm{m}} \cos \left(\mathrm{p} \theta_{\mathrm{r}}-\frac{2 \pi}{3}\right) \\
\mathrm{M}_{\mathrm{vw}}=\mathrm{M}_{\mathrm{wv}}=\mathrm{M}_{\mathrm{o}}-\mathrm{M}_{\mathrm{m}} \cos \left(\mathrm{p} \theta_{\mathrm{r}}\right) \\
\mathrm{M}_{\mathrm{wu}}=\mathrm{M}_{\mathrm{uw}}=\mathrm{M}_{\mathrm{o}}-\mathrm{M}_{\mathrm{m}} \cos \left(\mathrm{p} \theta_{\mathrm{r}}+\frac{2 \pi}{3}\right)
\end{array}\right]
$$

where $\mathrm{M}_{\mathrm{o}}$ is the component of mutual inductance and $\mathrm{M}_{\mathrm{m}}$ is the magnitude of fundamental component part

The components of transformation from stator to synchronous reference frame, the direct axis and quadrature axis of the proposed PMFSM are classified in Figure 4. The rotor position, quadrature axis is chosen at the position A1 where the PM flux linkage is at peak level, and the q-axis is anti-clockwise. The 24S-14P PMFSM, displacement between the axes, is $6.4^{\circ}$ (mechanical degrees). Furthermore, stator-to flux alignment based on synchronous rotor frame of reference, the three-phase stator to segmented rotor Park's transformation by matrix is given as:

$$
P=\frac{2}{3}\left[\begin{array}{ccr}
\cos \theta_{\mathrm{c}} & \cos \left(\theta_{\mathrm{c}}-\frac{2 \pi}{3}\right) & \cos \left(\theta_{\mathrm{c}}+\frac{2 \pi}{3}\right) \\
-\sin \theta_{c} & -\sin \left(\theta_{c}-\frac{2 \pi}{3}\right) & -\sin \left(\theta_{c}+\frac{2 \pi}{3}\right) \\
\frac{1}{2} & \frac{1}{2} & \frac{1}{2}
\end{array}\right]
$$

where $\theta_{c}$ is the rotor position between the coil A1 and the direct axis $\mathrm{p} \theta_{\mathrm{r}}$ in Figure 4 .

More so, combining (1) and (4), PM flux linkages in the rotor reference frame is as transformed:

$$
\left[\begin{array}{l}
\psi_{m d}=\psi_{m} \\
\psi_{m q}=0
\end{array}\right]
$$


the (4) shows the transformed d-axis PM flux linkage is identical and also the linkage in q-axis is zero (0). Obviously, the transformed three-phase inductance component in rotor frame is given as stated in (1.5):

$$
\begin{aligned}
& {\left[\begin{array}{l}
\mathrm{L}_{\mathrm{d}}=\mathrm{L}_{\mathrm{o}}-\mathrm{M}_{\mathrm{o}}-1.5 \mathrm{~L}_{\mathrm{m}} \\
\mathrm{L}_{\mathrm{q}}=\mathrm{L}_{\mathrm{o}}-\mathrm{M}_{\mathrm{o}}+1.5 \mathrm{~L}_{\mathrm{m}} \\
\mathrm{L}_{\mathrm{o}}=\mathrm{L}_{\mathrm{dq}}=\mathrm{L}_{\mathrm{qd}}=\mathrm{L}_{\mathrm{d} 0}=0
\end{array}\right]} \\
& {\left[\begin{array}{l}
\mathrm{L}_{\mathrm{o}}-\mathrm{M}_{\mathrm{o}}=0.5\left(\mathrm{~L}_{\mathrm{d}}+\mathrm{L}_{\mathrm{q}}\right) \\
\mathrm{L}_{\mathrm{m}}=\frac{\mathrm{L}_{\mathrm{d}}-\mathrm{L}_{\mathrm{q}}}{3}
\end{array}\right]}
\end{aligned}
$$

where $\mathrm{L}_{\mathrm{d}}, \mathrm{L}_{\mathrm{o}}, \mathrm{L}_{\mathrm{q},}, \mathrm{L}_{\mathrm{dq}}, \mathrm{L}_{\mathrm{qd}}$ are inductance components transformed in rotor reference frame. therefore, the sum of d-axis and q-axis flux linkages expression confirm the equation stated:

$$
\begin{aligned}
& {\left[\begin{array}{l}
\psi_{\mathrm{d}}=\mathrm{L}_{\mathrm{d}} \mathrm{i}_{\mathrm{d}}=\psi_{\mathrm{m}}+\left(\mathrm{L}_{\mathrm{o}}-\mathrm{M}_{\mathrm{o}}-1.5 \mathrm{~L}_{\mathrm{m}}\right) \mathrm{i}_{\mathrm{d}} \\
\psi_{\mathrm{q}}=\mathrm{L}_{\mathrm{q}} \mathrm{i}_{\mathrm{q}}=\left(\mathrm{L}_{\mathrm{o}}-\mathrm{M}_{\mathrm{o}}-1.5 \mathrm{~L}_{\mathrm{m}}\right) \mathrm{i}_{\mathrm{q}}
\end{array}\right]} \\
& {\left[\begin{array}{l}
\mathrm{V}_{\mathrm{d}}=\frac{\partial \psi_{\mathrm{d}}}{\partial \mathrm{t}}-\omega_{\mathrm{c}} \psi_{\mathrm{q}}+\mathrm{R}_{\mathrm{c}} \mathrm{i}_{\mathrm{d}}=-\mathrm{p}_{\mathrm{r}} \omega_{\mathrm{r}} \mathrm{L}_{\mathrm{q}} \mathrm{i}_{\mathrm{q}}+\mathrm{R}_{\mathrm{c}} \mathrm{i}_{\mathrm{d}} \\
\mathrm{V}_{\mathrm{q}}=\frac{\partial \psi_{\mathrm{q}}}{\partial \mathrm{t}}+\omega_{\mathrm{c}} \psi_{\mathrm{d}}=\mathrm{p}_{\mathrm{r}} \omega_{\mathrm{r}} \psi_{\mathrm{m}}+\mathrm{p}_{\mathrm{r}} \omega_{\mathrm{r}} \mathrm{L}_{\mathrm{d}} \mathrm{i}_{\mathrm{d}}+\mathrm{R}_{\mathrm{c}} \mathrm{i}_{\mathrm{d}}
\end{array}\right]}
\end{aligned}
$$

where $\mathrm{R}_{c}$ is the reactance of the coil and $\mathrm{p}_{\mathrm{r}}$ is the rotor pole number more so, frequency of inverter is linked to the speed of rotor, is expressed as

$$
\omega_{\mathrm{c}}=\mathrm{p} \omega_{\mathrm{r}}
$$

the electromagnetic torque, $\mathrm{T}_{\mathrm{em}}$ is given as

$$
\mathrm{T}_{\mathrm{em}}=1.5 \mathrm{p}_{\mathrm{r}}\left\lfloor\psi_{\mathrm{m}} \mathrm{i}_{\mathrm{q}}+\left(\mathrm{L}_{\mathrm{d}}-\mathrm{L}_{\mathrm{q}}\right) \mathrm{i}_{\mathrm{d}} \mathrm{i}_{\mathrm{q}}\right\rfloor
$$

therefore, (11) shows that electromagnetic torque of magnetic field of rotor permanent magnet and stator permanent magnet is the same.

\subsection{Motor design parameters and specifications}

Design of the proposed and optimized PMFSM_model, was conducted using JMAG Geometry Editor. The motor parts and materials which are rotor, stator, armature coil and PM were designed and setting of the materials, conditions, circuit mesh setting are developed in the Designer. The material for the rotor and stator is electrical steel $35 \mathrm{H} 210$ and the PM is Neomax-35AH. The electrical restrictions related with the input voltage and DC inverter are restricted. Radius of motor, stack length, and shaft radius respectively are $139.7 \mathrm{~mm}, 100 \mathrm{~mm}$ and $30 \mathrm{~mm}$. The motor design employed the commercial 2D-FEA package. The PM consideration of locating on the tip of the stator teeth provides the following advantages which include permission of extending the span of PM at the tip and further protects it from the heat source proximity. Meanwhile, material of PM has the residual flux density and coercive force at $20^{\circ} \mathrm{C}$ are $1.2 \mathrm{~T}$ and $932 \mathrm{kA} / \mathrm{m}$. More so, the external rotor shaft is aluminum employed as an external envelop to secure the segmented rotor. 


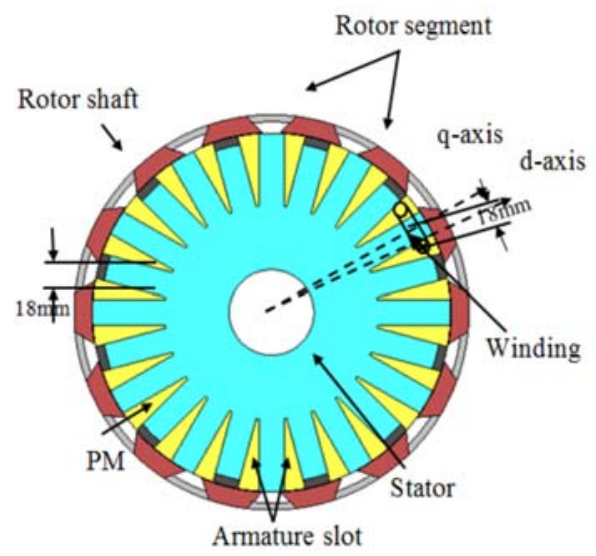

Figure 4: Cross-sections of optimized 24S-14P SegOR- PMFSM and considerations of d-axis and q-axis

\subsection{Rotor pole length, segment span and rotor width}

Among the sensitive design parameters on the part of rotor include, rotor length, segment span and rotor width respectively for torque enhancement. In the improved design Figure 4, rotor segment length has been optimised from intial value of $20.5 \mathrm{~cm}$ to $12.5 \mathrm{~mm}$, segment span is 20 degrees and rotor width is $26.5 \mathrm{~mm}$. Meanwhile, optimizing rotor parameters provided much gains in the generation of high torque as in Figure 5 (a), Figure 5 (b) and Figure 5 (c) respectively. Similarly, Stator pole arc width of the motor is also a sensitive part that influences magnet appropriate dimension and lamination size hence, the high performance of the motor. The impact of the stator pole arc on the performance is estimated by the finite element analysis and the stator width not placed with PM is now optimized resulting to maximum torque of $470 \mathrm{Nm}$. Figure 5 (d) shows the plot of torque against stator pole width yielding the highest output torque of the motor.

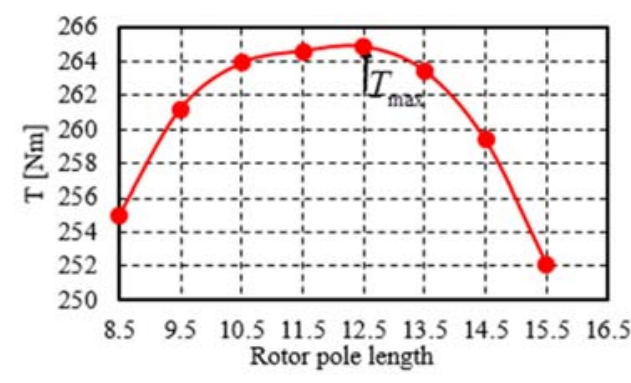

(a)

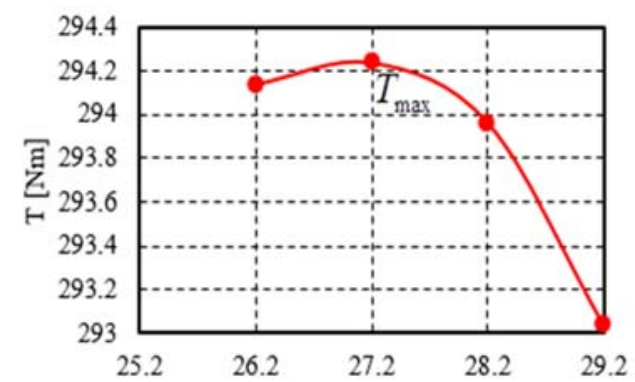

(c)

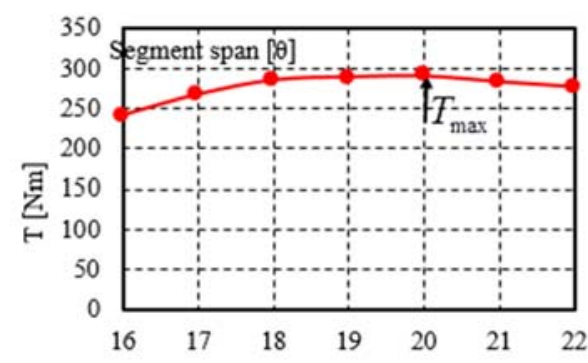

(b)

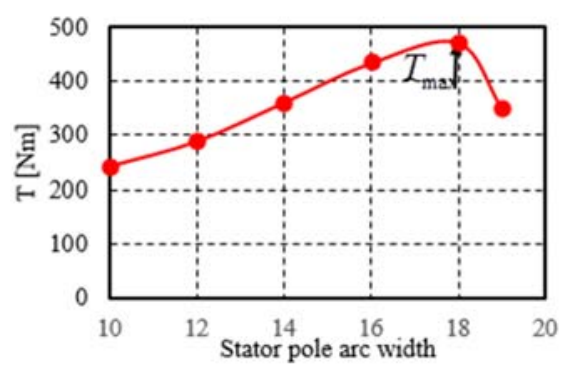

(d)

Figure 5. Effects of parameter optimization on torque on the optimized motor 


\section{RESULTS AND ANALYSIS}

This section, reports the 2D-FEA simulation results of the optimised motor in terms of cogging torque, torque against current density, average torque and, torque and power against speed in the following subsections:

\subsection{Motor's performance under no-load condition}

The optimized PMFS motor of $279.4 \mathrm{~mm}$ in size and utilizing PM $1 \mathrm{~kg}$ has been investigated under no-load condition to ascertain its level of performance. These include cogging torque, induced back-EMF, space harmonics and average torque which is expected to sustain acceleration. Figure 6 (a) presents the motor cogging torque between the improved and the optimized design in which optimised is lower than initial, with gain sto operate in safe region. In FSM, cogging torque is due to the interaction between the permanent magnets on the stator with stator slots winding and rotating rotor which causes vibration in motors. Meanwhile, the normal quantity for safe motor operation is $10 \%$ of the output torque $[5,15]$. Looking at the plot, optimized design achieved cogging torque lower than the improved design making it more favourable to operate safely. Furthermore, the stator pole width had reduced harmonics order when it was increased from $5 \mathrm{~mm}$ to $18 \mathrm{~mm}$ thus, reducing the cogging torque from $25 \mathrm{Nm}$ peak to peak to $20 \mathrm{Nm}$ peak to peak. The motor's simulated cogging torque is presented in

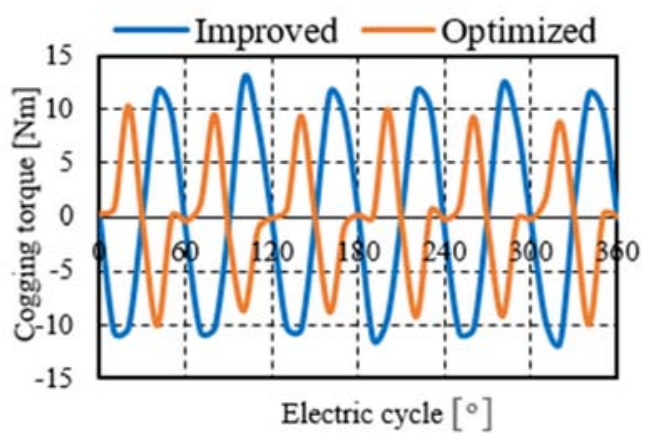

(a)

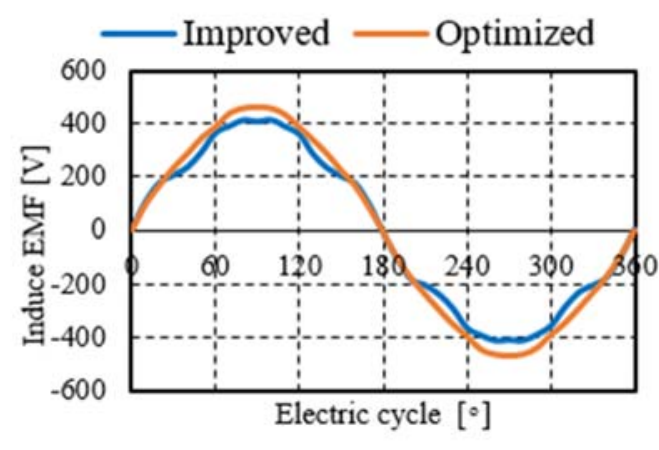

(b)

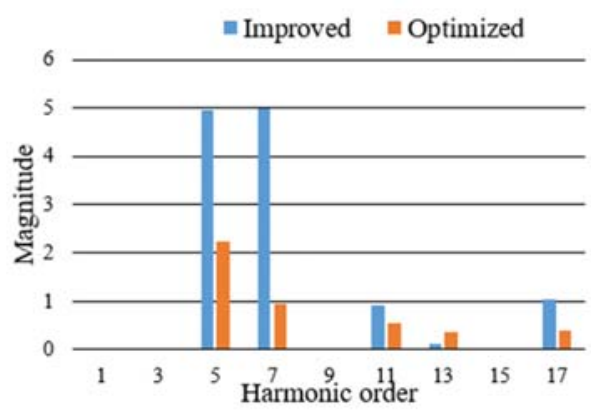

(c)

Figure 6. Motor's performance characteristics under no-load condition,

(a) cogging torque characteristics, (b) induced back-emf comparison, (c) magnitude order of harmonics with stator pole width

Figure 6 (a). Similarly, plot of the induced EMF is presented in Figure 6 (b) in which the optimized structure is seen to achieve pure sinusoidal waveform though, possessing voltage of $480 \mathrm{~V}$. The improved design achieved almost $400 \mathrm{~V}$ but was laced with distortion which is not favorable for motor smooth operation [22]. Figure 6 (c) illustrates the plot of harmonics order comparison of improved and optimized design. The plot depicts favourable harmonic reduction outcome from design optimisation in the 5th and 7 th order respectively. 


\subsection{Motor's performance under load condition}

The torque versus current density $J_{a} \mathrm{~A} / \mathrm{mm}^{2}$ characteristics of the motor, was conducted at different current values densities, Ja $5 \mathrm{~A} / \mathrm{mm}^{2}$ to $J a 30 \mathrm{~A} / \mathrm{mm}^{2}$ respectively as shown in Figure 7 (a). In the plot, output torque is seen to rise linearly at low current values but did not continue at high current density presenting that torque generation is not proportional to armature current density due to flux leakage. Therefore, optimized motor achieved torque of $470 \mathrm{Nm}$ which is obtained at $J_{a} 30 \mathrm{~A} / \mathrm{mm}^{2}$. Meanwhile, the torque versus speed characteristics curve is presented in Figure 7 (b) in which at the base speed of $898.45 \mathrm{rev} / \mathrm{min}$, the maximum torque is $470 \mathrm{Nm}$ at constant torque load and motor's speed will begin to decrease if operated beyond the base speed. Furthermore, the plot of output torque and power versus speed characteristics is presented in Figure 7 (c). Power performance shows that at base speed and maximum torque, maximum output power is $45 \mathrm{~kW}$ at constant torque load but it dropped low and remained constant throughout the entire speed region.

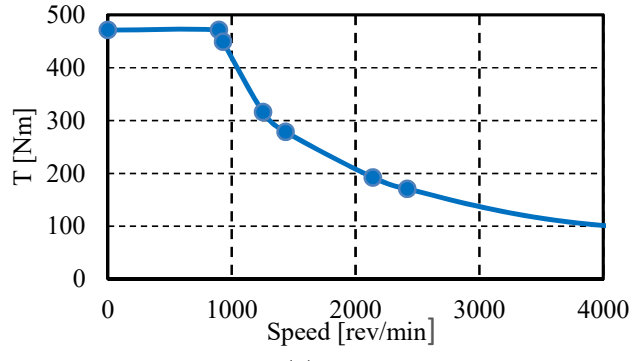

(a)

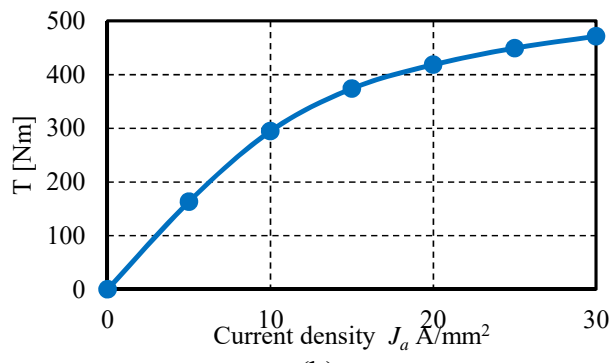

(b)

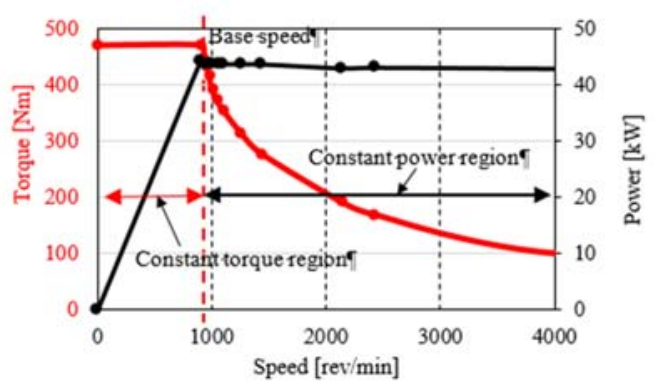

(c) Plot of average torque and power versus speed of optimised design

Figure 7. Motor's performance characteristics under load condition, (a) torque versus armature current density, (b) torque versus speed of optimized design, (c) plot of average torque and power versus speed of optimised design

\section{CONCLUSION}

Permanent magnet motor technology for high torque as viable solution for clean vehicle propulsion drive has been presented with clear cut of its advantages. It consists of unconventional 14 segmented rotor poles having an external rotor shaft to secure retainment for speed operation. The JMAG Tool Solver is utilized for 2D finite element analysis to investigate motor's performances in terms of cogging torque, induced EMF and average output torque. The optimized design has a reduced cogging torque to operate in a safe region, induced EMF has a smooth sinusoidal waveform, though with higher value which is common with every permanent magnet motor. High torque is crucially significant as inertia overcomer and acceleration sustainer. From simulation analysis, the optimised motor achieved average torque of $470 \mathrm{Nm}$ with power of $45 \mathrm{~kW}$ at the speed of $898 \mathrm{rev} / \mathrm{min}$. Therefore, the proposed PMFSM in segmented rotor, has proven to be reliable for in-wheel application providing excellent performance better than PMSM, which achieved $110 \mathrm{Nm}$ and $6 \mathrm{~kW}$.

Int J Pow Elec \& Dri Syst, Vol. 10, No. 2, June 2019 : 575 - 584 


\section{ACKNOWLEDGEMENTS}

This research work was sponsored by Research, \& Management Centre, Universiti Tun Hussein Onn Malaysia (UTHM) and FRGS Grant Vot 1651 under Ministry of Education, Malaysia.

\section{REFERENCES}

[1] S. K. Bhattacharya, Electrical Machines. New Delhi, India, McGraw Hill Education (India) Private Limited, pp. 57, 2014.

[2] M. Z. Ahmad, et al., "Preliminary studies on a new outer-rotor permanent magnet flux switching machine with hybrid excitation flux for direct drive EV application," in Proc. IEEE Inter. Conf., Power and Energy, pp. 928-933, 2012.

[3] W. Fei, et al., "A novel outer-rotor permanent magnet flux switching machine for urban electric vehicle applications," in Pro. $3^{\text {rd }}$ Inter. Conf., Power Elect. Systems Applications, pp. 1-6, 2009.

[4] M. F. Omar, et al., "A new topology of single phase field excitation flux switching machine for high density aircondition with segmental rotor," ARPN Journal of Engineering and Applied Sciences, 2013.

[5] E. I. Mbadiwe and E. Sulaiman, "Flux switching permanent magnet motor using segmented outer rotor structure for electric scooter," Indonesian Journal of Electrical Engineering and Computer Science (IJEECS), Vol. 6 (2), pp. 379-386, 2017.

[6] S. Erwan, et al., "Improved design of three phase hybrid excitation flux switching motor with segmental rotor," 9th International Power Engineering and Optimization Conference, (PEOCO), 2015.

[7] C. S. Walker et al., "High torque density high efficiency flux switching machine for aerospace application," IEEE Journal of Emerging and Selected Topics in Power Electronics, Vol. 1, pp. 327-336, 2013.

[8] E. Sulaiman, et al. "Development of high torque and high power density hybrid excitation flux switching motor for traction drive in hybrid electric vehicle," Energy and Power Engineering, 2013, pp. 446-454.

[9] S. Byeong, et al., "Design of an outer-rotor-type permanent magnet rotor for electric scooter propulsion systems," International Power Electronics Conference, 2010.

[10] H. Zang, et al., "Design and analysis of synchronous motor employing a segmental rotor type 12/8 Switched reluctance motor", Journal of Power Electronics. vol. 14, pp. 866-873, 2014.

[11] M. Galea, et al., "Design considerations for an outer rotor field wound, flux switching machine," XXth inter. Conference on Electrical Machines, (ICEM), Nov. 2012.

[12] N. Bianchi, et al., "High performance PM synchronous motor drive for an electrical scooter," IEEE Transactions on Industry Applications, vol. 37, pp. 1348-1355, 2001.

[13] A. Zulu, et al., "Topologies for wound field three phase segmented rotor flux switching machines," in 5th international Conference on Power Electronics, Machines and Drives (PEMD), pp. 1-6, 2010.

[14] T. Celik, et al., Ph.D. Thesis, University of Newcastle upon Tyne School of Electrical, Electronic and Computer Engineering UK, 2011.

[15] S. M. Alexander, et al., "Environmental assessment of full electric transportation portfolio," Greenhouse Gas Emission, Electric Power Research Institute, pp. 152, 2015

[16] S. Rauch and L. J. Johnson, "Design principles of flux-switching alternators," AIEE Trans. 74III, pp.1261-1268, 1955.

[17] E. Hoang, et al., "Switching flux permannet magnet polyphase synchronous machines," in Proc. 7 Eur. Conference Power Electronic Applications, vol. 3, pp. 903-908, 1997.

[18] G. D. David, et al., "Alternative rotor designs for high performance brushless permanent magnet machines for hybrid electric vehicles", IEE Transactions on Magnetics, 2012, pp. 835-838.

[19] A. S. Thomas, et al., "Comparison of flux switching and surface mounted permanent magnet generators for aerospace applications," in Proc, IET PEMD, pp. 1-5, 2010.

[20] H. Jia, et al., "Investigation and implementation of control strategies for flux-switching permanent magnet motor drives", IEEE, Industry Applications Society Annual Meeting, October, 2008.

[21] Y. Amamra et al., "Hybrid Excitation Synchronous Machines: Energy Efficient Solution for Electric Vehicles Propulsion," IEEE Vehicle Power Propulsion Conference, vol. 58, pp. 1-6, 2006.

[22] X. Liang, et al., "Harmonics analysis in induction motors", Conference on Electrical and Computer Engineering, (CCECE), May 2006. 


\section{BIOGRAPHIES OF AUTHORS}

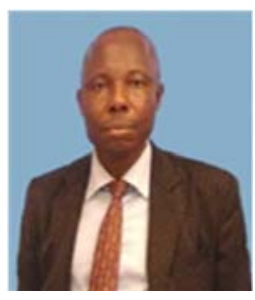

Enwelum I. Mbadiwe received his B.Eng. degree in electrical engineering from Enugu State University of Science and Technology Nigeria in 1995, M. Eng degree in power devices from University of Nigeria in 2010 and currently, Ph. D Research Student at Universiti Tun Hussein Onn Malaysia. His research interest is on flux switching machine in segmented rotor for inwheel vehicle applications. He is an Academic Staff at Niger State Polytechnic, Zungeru, Nigeria since December 1996.

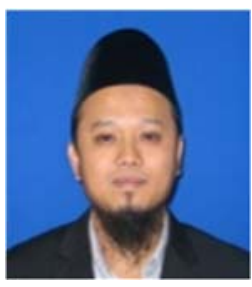

Erwan Sulaiman received his B. E and M. E degrees in Electrical Engineering from Universiti of Malaya in 2001 and Universiti Tun Hussein Onn Malaysia (UTHM) in 2004 and has been with the Universiti as a Lecturer. He received his Doctor in Electrical Engineering from Nagoya Institute of Technology (NIT) Japan in 2012. His research interests include optimization of HEFSM, WFFSM, in particular for HEV drive applications. He is currently senior lecturer at Department of applications. He is currently senior lecturer at Department of Electrical Power Engineering, Universiti Tun Hussein Onn Malaysia.

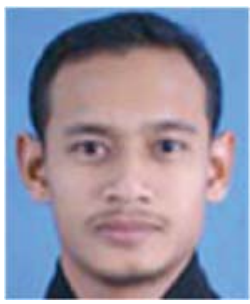

M. Z. Ahmad received his BE degree in electrical engineering from University Technology Mara in 2003 and ME degree in electrical engineering from University Technology Malaysia in 2006. He has been a lecturer at University Tun Hussein Onn Malaysia since 2006 where he received his $\mathrm{Ph}$. D in 2017. His research interests include electric machine design and drive control. 